\title{
The correlation between heart failure and the risk of ischemic colitis: a systematic review and meta-analysis
}

\author{
Wasit Wongtrakula ${ }^{a}$ Nipith Charoenngnamb ${ }^{b}$ Patompong Ungprasertc \\ Mahidol University, Bangkok, Thailand; Cleveland Clinic, Cleveland, Ohio, USA
}

\section{Abstract}

\begin{abstract}
Background Ischemic colitis is a relatively common gastrointestinal disease caused by hypoperfusion of the colon. Recently, studies have suggested an association between heart failure (HF) and ischemic colitis, even though the magnitude of the reported association varied considerably across the studies. This systematic review and meta-analysis were performed to comprehensively explore whether patients with $\mathrm{HF}$ are at a higher risk of ischemic colitis compared with individuals without $\mathrm{HF}$ by combining the results of all available observational studies.
\end{abstract}

Methods Systematic literature review was performed using EMBASE, MEDLINE and Google Scholar database up to May 2020. Eligible studies could be any observational ones that evaluated whether patients with HF have a higher risk of ischemic colitis than individuals without HF. Point estimates and standard errors from each eligible study were combined together using the generic inverse variance method of DerSimonian and Laird.

Results The systematic review identified 7 case-control studies and 1 cross-sectional study. The pooled analysis found that patients with HF had a significantly higher risk of ischemic colitis with the pooled odds ratio of 3.42 (95\% confidence interval 1.49-7.82; $I^{2} 96 \%$ ). Funnel plot was relatively symmetric and was not suggestive of presence of publication bias.

Conclusion A significantly increased risk of ischemic colitis among patients with HF was demonstrated in this systematic review and meta-analysis.

Keywords Heart failure, ischemic colitis, epidemiology, meta-analysis, systematic review

Ann Gastroenterol 2021; 35 (1): 1-10

\section{Introduction}

Heart failure (HF) is a syndrome caused by cardiac abnormalities and neurohormonal changes, leading to elevated intracardiac pressures or reduced cardiac output [1]. The estimated incidence rate is approximately $300-400$ new cases per 100,000 person-years, causing substantial healthcare and economic burden [2-5]. Symptoms and

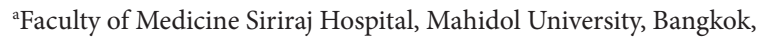

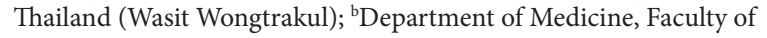
Medicine Siriraj Hospital, Mahidol University, Bangkok, Thailand (Nipith Charoenngnam); 'Department of Rheumatic and Immunologic Diseases, Cleveland Clinic, Cleveland, Ohio, USA (Patompong Ungprasert)

Conflict of Interest: None

Correspondence to: Nipith Charoenngam, 2 Prannok Road, Bangkoknoi, 10700 Bangkok, Thailand, e-mail: nipith.charoenngam@ gmail.com

Received 2 September 2020; accepted 30 November 2020; published online 5 February 2021

DOI: https://doi.org/10.20524/aog.2021.0596 signs of HF include dyspnea, orthopnea, fatigue, peripheral edema, raised jugular venous pressure, cardiomegaly, and a third heart sound [6]. Common etiologies of HF are myocardial infarction, hypertension, valvular heart disease and cardiomyopathy [6].

With an incidence ranging from 4.5-45 new cases per 100,000 person-years $[7,8]$, ischemic colitis is a relatively common gastrointestinal disease caused by hypoperfusion to the colon, leading to inflammation and hemorrhage of intestinal mucosa [9]. Classical clinical presentation of ischemic colitis is hematochezia and lower abdominal pain in patients aged older than 60 years [10]. Any conditions that can impair colonic perfusion, such as arterial emboli, thrombosis, trauma, hypotension and shock can predispose patients to ischemic colitis [10].

Recently, studies have suggested a relationship between $\mathrm{HF}$ and ischemic colitis, even though the magnitude of the reported association varied considerably [8,11-17]. Therefore, this systematic review and meta-analysis was performed to comprehensively explore whether patients with $\mathrm{HF}$ are at a higher risk of ischemic colitis compared with individuals without $\mathrm{HF}$ by combining the results of all available observational studies. 


\section{Materials and methods}

\section{Information sources and search strategy}

Two authors (W.W. and N.C.) independently conducted systematic literature review with no language limitation in EMBASE and MEDLINE database from inception to May 2020 to identify all published articles that explored the association between HF and ischemic colitis. The search strategy that includes the terms for "heart failure" and "ischemic colitis" is available as Supplementary Data 1. To maximize the comprehensiveness of the identification of eligible studies, the literature review was also performed in Google Scholar and bibliography of the included studies initially retrieved from EMBASE and MEDLINE. This study was performed according to the Preferred Reporting Items for Systematic Reviews and Meta-Analyses statement (Supplementary Data 2).

\section{Selection criteria}

Eligible studies could be any observational ones that evaluated whether patients with HF have a higher risk of ischemic colitis than individuals without HF. Eligible cohort studies had to provide relative risks, incidence rate ratios, hazard risk ratios, or standardized incidence ratios with associated 95\% confidence interval (CI) comparing the incidence of ischemic colitis between the 2 cohorts. Eligible case-control studies had to report odds ratios (OR) with 95\%CI comparing the prevalence of HF between cases and controls. Eligible cross-sectional studies had to report OR with $95 \%$ CI of the association.

\section{Data extraction}

Standardized data collection form was used to extract the following details: last name of the first author; country of study; study design; year of publication; number of participants; recruitment of participants; identification and ascertainment of the diagnosis of HF and ischemic colitis; mean age of participants; percentage of male participants; confounders adjusted in multivariate analysis; and adjusted effect estimates with corresponding 95\%CI. Two authors (W.W. and N.C.) assessed the quality of each cohort study according to Newcastle-Ottawa quality assessment scale [18].

\section{Statistical analysis}

Review Manager 5.3 software from the Cochrane Collaboration (London, United Kingdom) was used for all statistical analyses. To pool point estimates of all eligible studies together, the generic inverse variance method of DerSimonian and Laird was utilized in which the weight of each study for the pooled analysis was in reversal to its standard error [19]. Randomeffect model, rather than fixed-effect model, was utilized as the eligible studies had different background populations and protocols. Cochran's Q test was utilized to determine statistical heterogeneity, further complemented by $I^{2}$ statistic which quantified the proportion of the total variation across studies incurring from heterogeneity rather than coincidence. A value of $I^{2}$ of $0-25 \%$ represented insignificant heterogeneity; $26-50 \%$ low heterogeneity; 51-75\% moderate heterogeneity; and $>75 \%$ high heterogeneity [20]. Visualization of funnel plot was used to evaluate for the presence of publication bias.

\section{Results}

A total of 1,336 articles (1,246 from EMBASE and 90 from MEDLINE) were identified. Duplication of 78 articles were removed, leaving 1,258 articles for title and abstract review. After the first round of title and abstract review, 1,210 articles were excluded as they obviously did not meet the eligibility criteria based on study design and type of article. As a result, 48 articles underwent further full-text review in which 42 articles were excluded because they did not investigate the association of interest, leaving 6 eligible studies for the meta-analysis. Review of bibliography of those eligible studies yielded 1 additional eligible study. Also, 1 additional eligible study was retrieved from Google Scholar. Finally, 7 case-control studies and 1 crosssectional study were considered eligible and were included into the meta-analysis. Literature review and study selection process are summarized in Fig. 1. Description of study design, characteristics of participants and Newcastle-Ottawa assessment scales of the included studies are presented in Table 1.

\section{Risk of ischemic colitis among patients with HF}

As shown in Fig. 2, the pooled analysis found that patients with HF had a statistically significantly higher risk of developing ischemic colitis than individuals without HF with the pooled OR of 3.42 (95\%CI 1.49-7.82). The statistical heterogeneity was high with an $I^{2}$ of $96 \%$. The funnel plot of this meta-analysis was relatively symmetric and did not suggest the presence of publication bias (Fig. 3).

\section{Discussion}

This study is the first systematic review and meta-analysis to explore the risk of ischemic colitis among patients with HF. The pooled analysis found an approximately 3.4-fold increased risk of ischemic colitis. Concerning the potential mechanisms of this association, it is possible that ischemic colitis is a direct injury from reduced peripheral blood flow from low cardiac output in $\mathrm{HF}$, as hypoperfusion to the colon is the principal pathogenesis of ischemic colitis [9]. In the state of reduced cardiac output in HF, blood flow is preserved for vital organs such as brain and heart by increased sympathetic activation and splanchnic vasoconstriction, resulting in reduced peripheral blood flow to tissue in gastrointestinal systems including the colon $[21,22]$. 


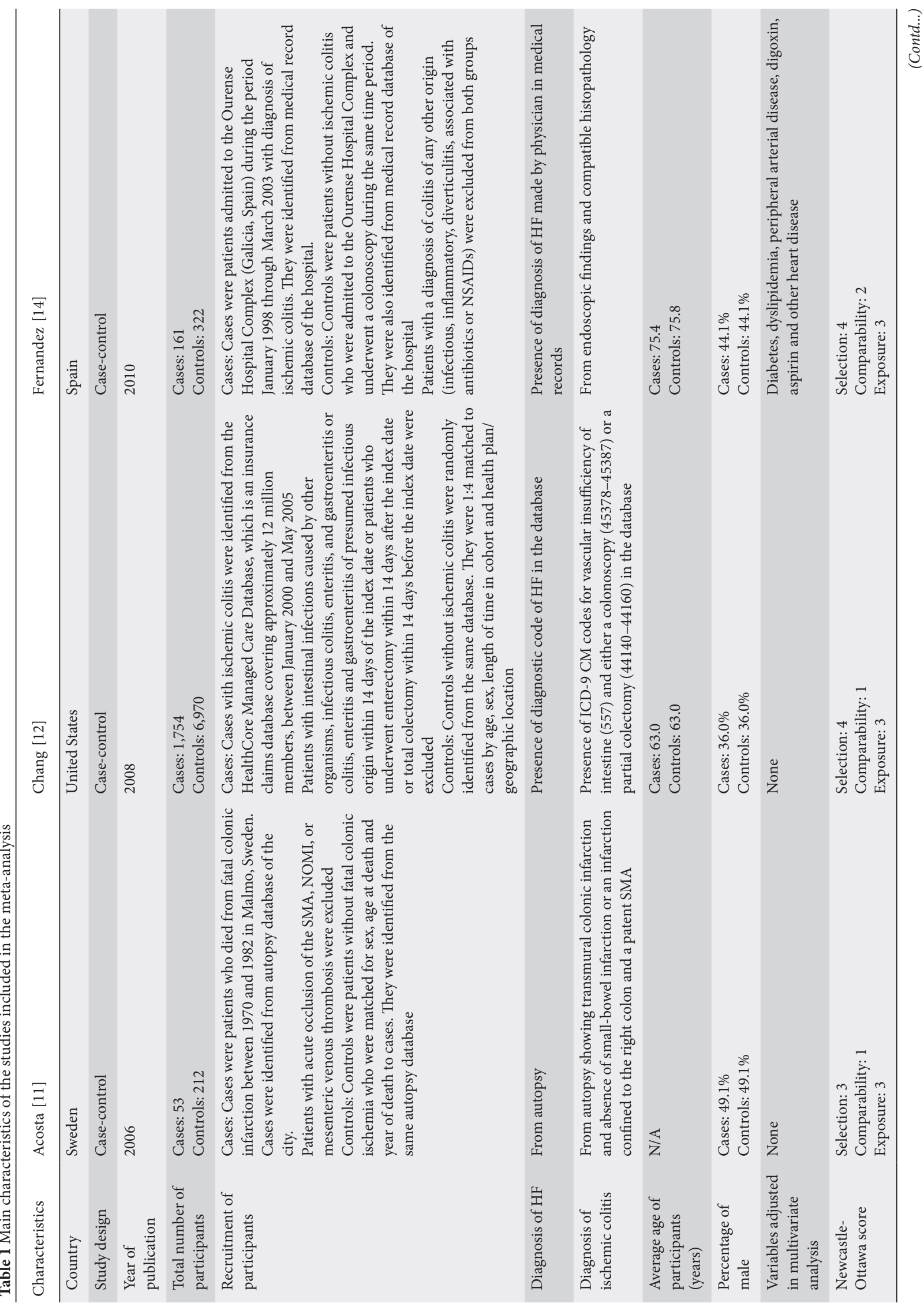




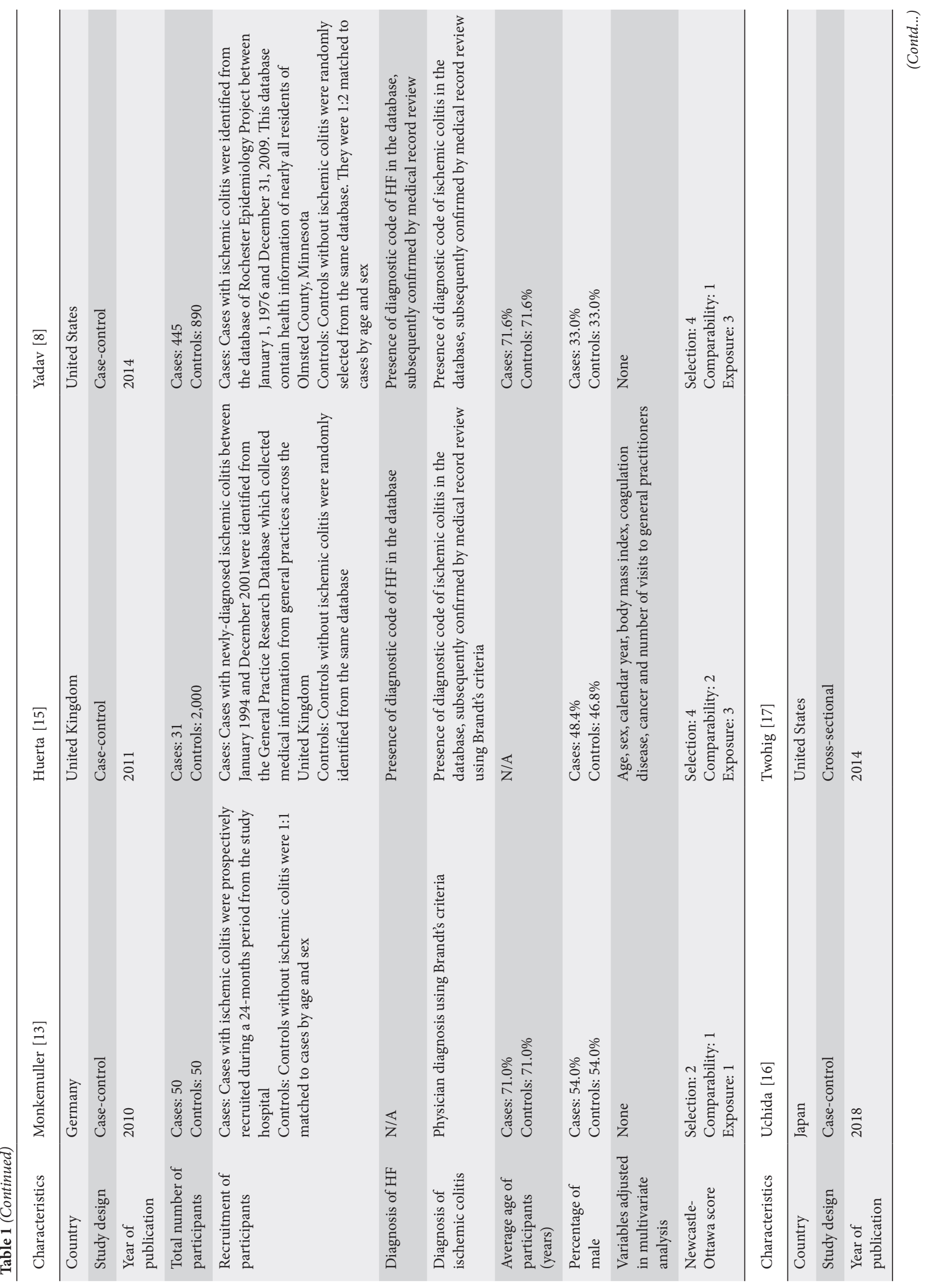


Heart failure and risk of ischemic colitis $\mathbf{5}$

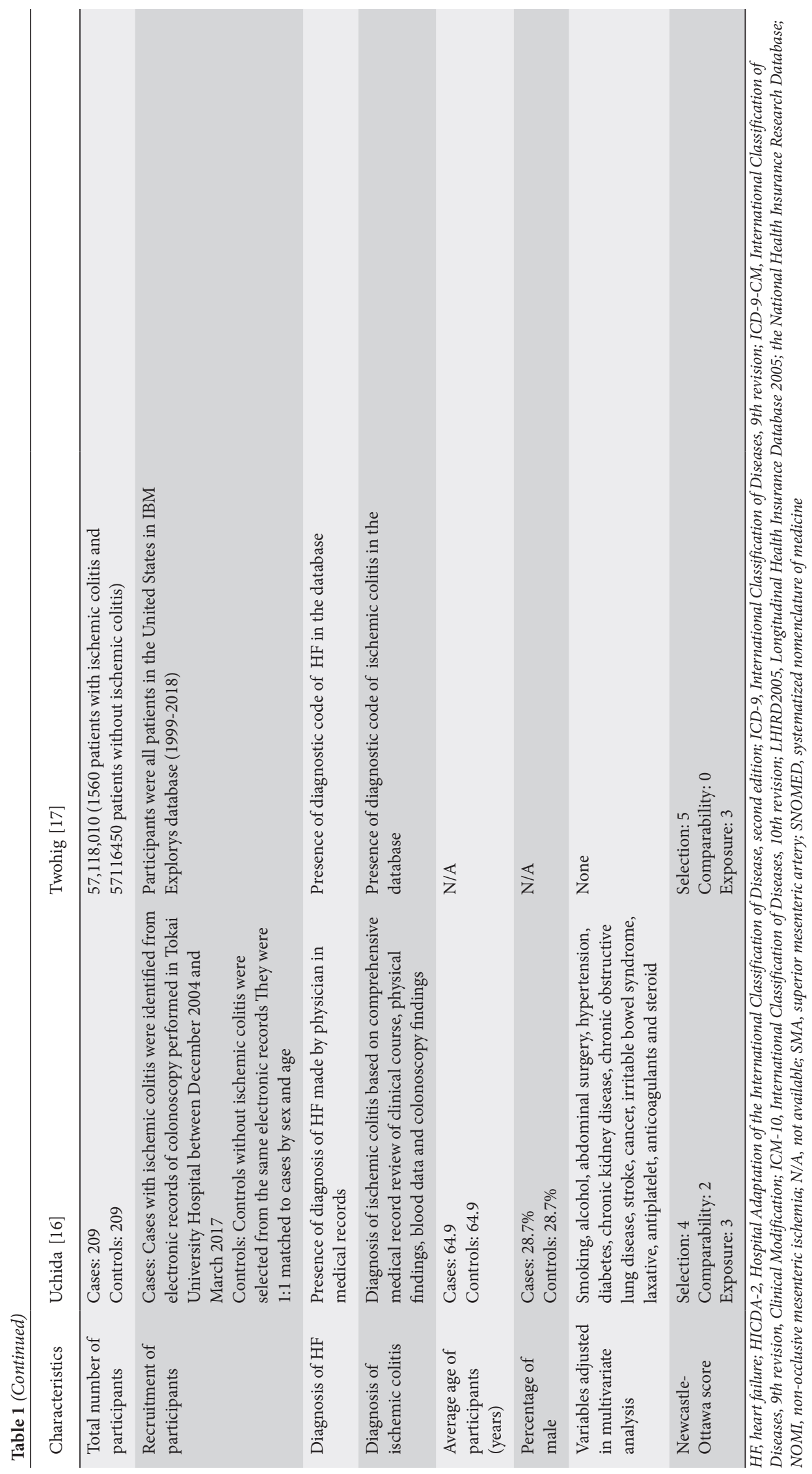


The circulation to the gastrointestinal tract could be further jeopardized by acute exacerbation of HF by any precipitating factors, such as excessive salt intake, arrhythmias [23] or infection [24], causing acute insufficiency of blood supply in the colon.

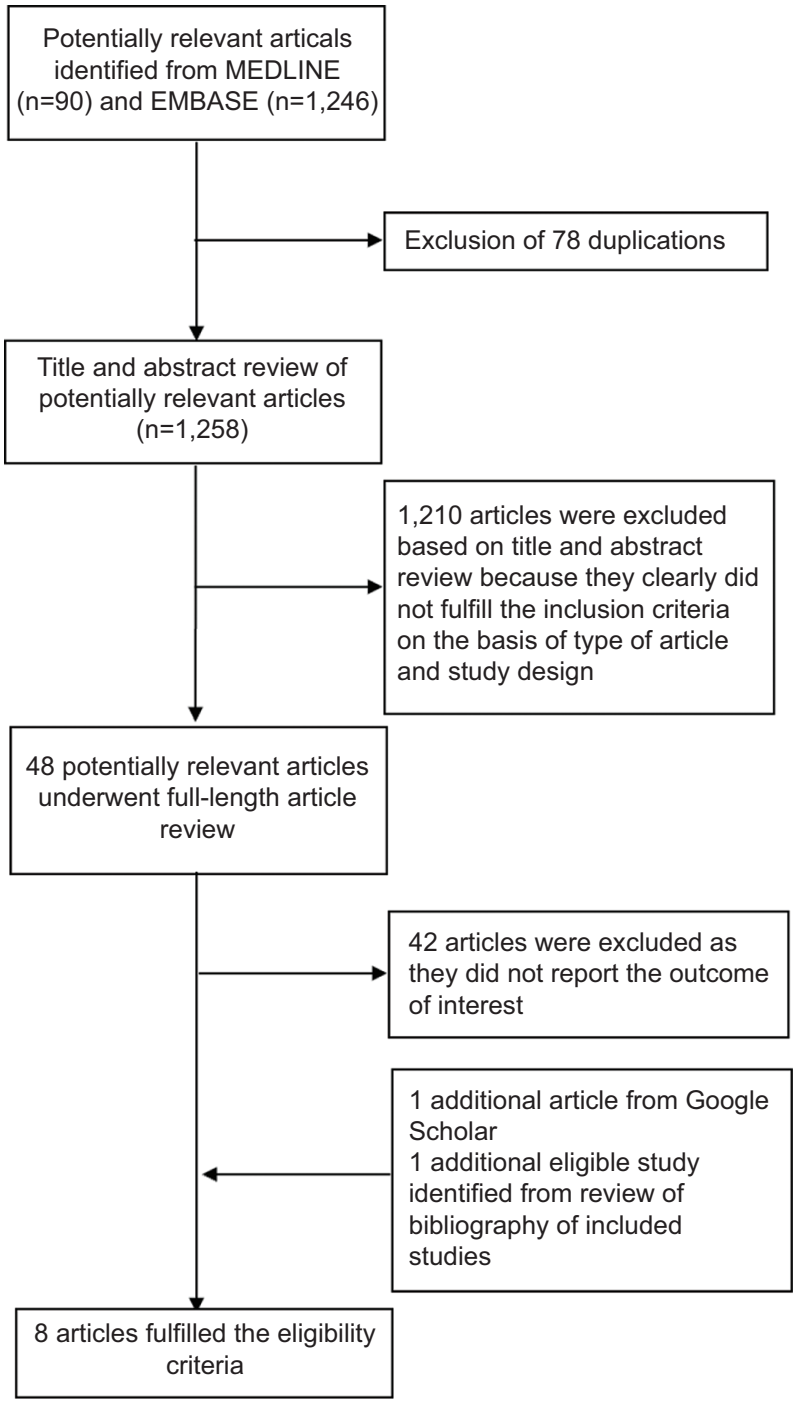

Figure 1 Literature review and study selection process
Another possible explanation is embolic phenomenon. It is well known that HF increases the risk of atrial fibrillation [25]. Increased intracardiac filling pressure, dysregulation of intracellular calcium of cardiac myocytes, and neurohormonal activation in HF contribute to atrial remodeling, fibrosis and development of atrial fibrillation [26]. Atrial fibrillation is a primary risk factor for systemic emboli [27]. Cardiac emboli to branches of inferior mesenteric artery can block blood supply to colon and cause ischemic colitis.

The increased risk may run through the shared atherosclerotic risk factors between the 2 conditions. The most common etiology of HF is coronary artery disease [28], a result of the narrowing of coronary artery by atherosclerotic plaque [29]. Therefore, risk factors of HF are similar to other atherosclerotic diseases, which include atherosclerotic occlusion of non-coronary vessels such as inferior mesenteric branches responsible for ischemic colitis [30].

This meta-analysis carries some limitations that should be recognized. First, the 5 studies $[8,12,14,15,17]$ included in this meta-analysis relied on registry data and diagnostic codes to diagnose HF and ischemic colitis, potentially jeopardizing the diagnostic accuracy and completeness of case identification. Second, only $2[14,16]$ of the 8 included studies adjusted their effect estimates for atherosclerotic risk factors (hypertension, dyslipidemia, diabetes mellitus, obesity, and smoking). Consequently, this association might be a result of those confounders rather than a true association. Also, only 2 studies $[14,16]$ had a perfect Newcastle-Ottawa score while the rest had only fair quality with the score ranging from 4-8 points, which may have jeopardized the validity of the pooled effect estimates. Additionally, due to the limited geographical distribution of the studies ( 3 studies from the United States, 4 studies from Europe, 1 study from Asia, and none from Africa and South America), the results may not be generalizable to every population. Last, even though funnel plot of this study is symmetric, the interpretation of this plot is limited by the relatively small number of eligible studies. Therefore, publication bias in favor of studies that report positive association may have been present.

In conclusion, a significantly increased risk of ischemic colitis among patients with HF was observed in this systematic review and meta-analysis.

\begin{tabular}{|c|c|c|c|c|c|c|c|c|c|}
\hline \multirow{2}{*}{$\begin{array}{l}\text { Study or Subgroup } \\
\text { Acosta et al. } 2006\end{array}$} & \multirow{2}{*}{$\begin{array}{r}\text { log[Odds Ratio] } \\
1.6487\end{array}$} & \multirow{2}{*}{$\begin{array}{r}\text { SE } \\
03158\end{array}$} & Weight & $\begin{array}{c}\text { Odds Ratio } \\
\text { IV, Random, } 95 \% \text { CI }\end{array}$ & \multirow{2}{*}{$\begin{array}{l}\text { Year } \\
2006\end{array}$} & \multicolumn{3}{|c|}{$\begin{array}{c}\text { Odds Ratio } \\
\text { IV, Random, } 95 \% \mathrm{CI}\end{array}$} & \\
\hline & & & $13.0 \%$ & $5.20[2.80,9.66]$ & & & & & \\
\hline Chang et al. 2008 & 0.2927 & 0.0915 & $13.9 \%$ & $1.34[1.12,1.60]$ & 2008 & & & $=$ & \\
\hline Monkemuller et al. 2010 & 0.2719 & 0.5233 & $11.5 \%$ & $1.31[0.47,3.66]$ & 2010 & & & & \\
\hline Fernandez et al. 2010 & 1.1537 & 0.4509 & $12.1 \%$ & $3.17[1.31,7.67]$ & 2010 & & & & \\
\hline Huerta et al. 2011 & 1.721 & 0.4712 & $11.9 \%$ & $5.59[2.22,14.08]$ & 2011 & & & & \\
\hline Yadav et al. 2014 & 1.411 & 0.2324 & $13.4 \%$ & $4.10[2.60,6.47]$ & 2014 & & & & \\
\hline Uchida et al. 2018 & 0.6831 & 0.6535 & $10.5 \%$ & $1.98[0.55,7.13]$ & 2018 & & & & \\
\hline Twohig et al. 2019 & 2.4596 & 0.1453 & $13.8 \%$ & $11.70[8.80,15.56]$ & 2019 & & & & $\varpi$ \\
\hline Total $(95 \% \mathrm{Cl})$ & & & $100.0 \%$ & $3.42[1.49,7.82]$ & & & & & \\
\hline \multicolumn{6}{|c|}{$\begin{array}{l}\text { Heterogeneity: } \text { Tau }^{2}=1.27 ; \mathrm{Chi}^{2}=172.64, \mathrm{df}=7(\mathrm{P}<0.00001) ; \mathrm{I}^{2}=96 \% \\
\text { Test for overall effect: } Z=2.91(\mathrm{P}=0.004)\end{array}$} & 0.05 & $\mathrm{H}^{2}(2-120$ & $\mathrm{HF}$ mo & 20 \\
\hline
\end{tabular}

Figure 2 Forest plot of meta-analysis of the association between heart failure (HF) and ischemic colitis (IC) CI, confidence interval; SE, standard error 


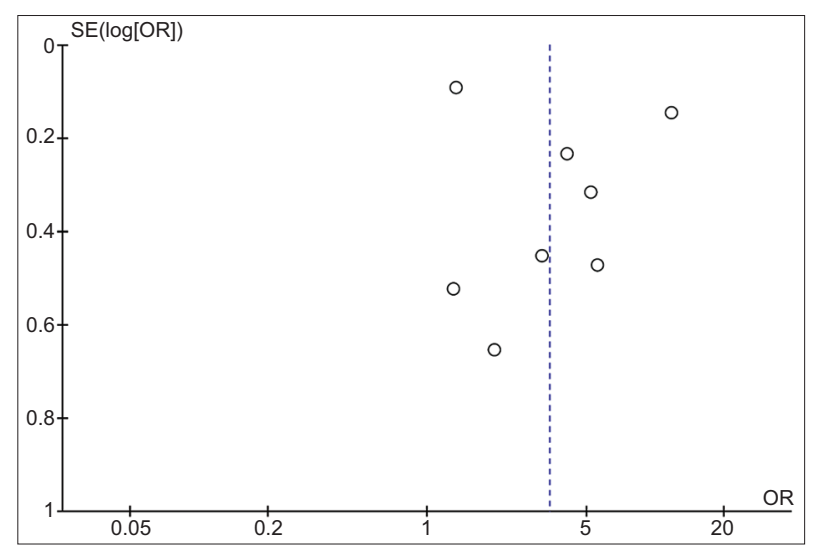

Figure 3 Funnel plot of meta-analysis of the association between heart failure and ischemic colitis

$O R$, odds ratio; SE, standard error

\section{Summary Box}

\section{What is already known:}

- Known risk factors of ischemic colitis include conditions that can impair colonic perfusion, such as arterial emboli, thrombosis, and hypotension

\section{What the new findings are:}

- The pooled analysis found that patients with heart failure had a significantly higher risk of developing ischemic colitis than individuals without heart failure

- Based on the pooled analysis of the 8 included studies, the risk was increased by approximately 3.4-fold

- Possible mechanisms were reduced colonic blood flow from low cardiac output and increased risk of embolic phenomenon

\section{References}

1. Metra M, Teerlink JR. Heart failure. Lancet 2017;390:1981-1995.

2. Conrad N, Judge A, Tran J, et al. Temporal trends and patterns in heart failure incidence: a population-based study of 4 million individuals. Lancet 2018;391:572-580.

3. Gomez-Soto FM, Andrey JL, Garcia-Egido AA, et al. Incidence and mortality of heart failure: a community-based study. Int J Cardiol 2011;151:40-45.

4. Roger VL, Weston SA, Redfield MM, et al. Trends in heart failure incidence and survival in a community-based population. JAMA 2004;292:344-350.

5. Ezekowitz JA, Kaul P, Bakal JA, Quan H, McAlister FA. Trends in heart failure care: has the incident diagnosis of heart failure shifted from the hospital to the emergency department and outpatient clinics? Eur J Heart Fail 2011;13:142-147.

6. McMurray JJV, Pfeffer MA. Heart failure. Lancet 2005;365:18771889.
7. Higgins PD, Davis KJ, Laine L. Systematic review: the epidemiology of ischaemic colitis. Aliment Pharmacol Ther 2004;19:729-738.

8. Yadav S, Dave M, Varayil JE, et al. Risk factors and outcomes of ischemic colitis in a population-based cohort. Am J Gastroenterol 2013;108(Suppl):S164-S165.

9. Trotter JM, Hunt L, Peter MB. Ischaemic colitis. BMJ 2016;355:i6600.

10. Theodoropoulou A, Koutroubakis IE. Ischemic colitis: clinical practice in diagnosis and treatment. World J Gastroenterol 2008; 14:7302-7308.

11. Acosta S, Ogren M, Sternby NH, Bergqvist D, Bjorck M. Fatal colonic ischemia: A population-based study. Scand J Gastroenterol 2006;41:1312-1319.

12. Chang L, Kahler K, Sarawate C, Quimbo R, Kralstein J. Assessment of potential risk factors associated with ischaemic colitis. Neurogastroenterol Motil 2008;20:36-42.

13. Monkemuller K, Hanus L, Zimmermann L, et al. Non-steroidal anti-inflammatory drugs (NSAIDS) increase the risk of ischemic colitis: A matched case-control study. Gastroenterology 2010;138(Suppl):S479.

14. Cubiella Fernández J, Núñez Calvo L, González Vázquez E, et al. Risk factors associated with the development of ischemic colitis. World J Gastroenterol 2010;16:4564-4569.

15. Huerta C, Rivero E, Montoro MA, García-Rodriguez LA. Risk factors for intestinal ischaemia among patients registered in a UK primary care database: A nested case-control study. Aliment Pharmacol Ther 2011;33:969-978.

16. Uchida T, Matsushima M, Orihashi Y, et al. A case-control study on the risk factors for ischemic colitis. Tokai J Exp Clin Med 2018;43:111-116.

17. Twohig P, Desai A, Skeans JM, Waghray N. Quantifying risk factors for ischemic colitis: a retrospective cohort study of 1560 patients. Gastroenterology 2019;156(Suppl):S-1072.

18. Wells GA, Shea B, O'Connell D, et al. The Newcastle-Ottawa scale (NOS) for assessing the quality of non-randomized studies in meta-analysis. Availble from: http://www.ohri.ca/programs/ clinical_epidemiology/oxford.asp [Accessed 9 January 2021].

19. DerSimonian R, Laird N. Meta-analysis in clinical trials. Control Clin Trials 1986;7:177-188.

20. Higgins JP, Thompson SG, Deeks JJ, Altman DG. Measuring inconsistency in meta-analyses. BMJ 2003;327:557-560.

21. Sandek A, Swidsinski A, Schroedl W, et al. Intestinal blood flow in patients with chronic heart failure: a link with bacterial growth, gastrointestinal symptoms, and cachexia. J Am Coll Cardiol 2014;64:1092-1102.

22. Sundaram V, Fang JC. Gastrointestinal and liver issues in heart failure. Circulation 2016;133:1696-1703.

23. Tsuyuki RT, McKelvie RS, Arnold JMO, et al. Acute precipitants of congestive heart failure exacerbations. Arch Intern Med 2001; 161:2337-2342

24. Diaz A, Ciocchini C, Esperatti M, Becerra A, Mainardi S, Farah A. Precipitating factors leading to decompensation of chronic heart failure in the elderly patient in South-American community hospital. J Geriatr Cardiol 2011;8:12-14.

25. Anter E, Jessup M, Callans DJ. Atrial fibrillation and heart failure. Circulation 2009;119:2516-2525.

26. Prabhu S, Voskoboinik A, Kaye DM, Kistler PM. Atrial fibrillation and heart failure - cause or effect? Heart Lung Circ 2017;26:967-974.

27. Menke J, Lüthje L, Kastrup A, Larsen J. Thromboembolism in atrial fibrillation. Am J Cardiol 2010;105:502-510.

28. Lala A, Desai AS. The role of coronary artery disease in heart failure. Heart Fail Clin 2014;10:353-365.

29. Nabel EG, Braunwald E. A tale of coronary artery disease and myocardial infarction. N Engl J Med 2012;366:54-63.

30. Scharff JR, Longo WE, Vartanian SM, Jacobs DL, Bahadursingh AN, Kaminski DL. Ischemic colitis: spectrum of disease and outcome. Surgery 2003; 134:624-629. 


\section{Supplementary material}

\section{Supplementary Data 1 Search strategy}

\section{EMBASE}

1. 'ischemic colitis'/exp OR 'ischemic colitis'

2. 'mesenteric ischemia'/exp OR 'mesenteric ischemia'

3. 'colitis'/exp OR 'colitis'

4. 'ischemia'/exp OR 'ischemia'

5. \#3 AND \#4

6. \#1 OR \#2 OR \#5

7. 'heart failure' OR 'heart failure'/exp

8. 'congestive heart failure' OR 'congestive heart failure'/exp

9. 'CHF' OR 'CHF'/exp

10. 'diastolic heart failure' OR 'diastolic heart failure'/exp

11. 'systolic heart failure' OR 'systolic heart failure'/exp

12.'systolic dysfunction'/exp OR 'left ventricular systolic dysfunction'/exp

13. \#7 OR \#8 OR \#9 OR \#10 OR \#11 OR \#12

14. \#6 AND \#13

\section{MEDLINE}

1. ischemic colitis.mp. or exp Ischemic Colitis/

2. mesenteric ischemia.mp. or exp Mesenteric Ischemia/

3. colitis.mp. or exp Colitis/

4. ischemia.mp. or exp Ischemia/

5. 3 and 4

6. 1 or 2 or 5

7. heart failure.mp. or exp Heart Failure/

8. diastolic heart failure.mp. or exp Heart Failure, Diastolic/

9. systolic heart failure.mp. or exp Heart Failure, Systolic/

10. CHF.mp.

11.7 or 8 or 9 or 10

12.6 and 11 


\section{Supplementary Data 2 Prisma}

\begin{tabular}{llll}
\hline Section/topic & $\#$ & Checklist item & Reported on page \# \\
\hline TITLE & 1 & Identify the report as a systematic review, meta-analysis, or both. & 1 \\
\hline Title & 2 & $\begin{array}{l}\text { Provide a structured summary including, as applicable: background; } \\
\text { objectives; data sources; } \\
\text { study eligibility criteria, participants, and interventions; study appraisal and } \\
\text { synthesis methods; results; } \\
\text { limitations; conclusions and implications of key findings; systematic review } \\
\text { registration number. }\end{array}$ \\
\hline Structured summary & & 1 \\
\hline
\end{tabular}

INTRODUCTION

\begin{tabular}{lcl}
\hline Rationale & 3 & $\begin{array}{l}\text { Describe the rationale for the review in the context of what is already known. } \\
\text { Objectives }\end{array}$ \\
& $\begin{array}{l}\text { Provide an explicit statement of questions being addressed with reference } \\
\text { to participants, interventions, comparisons, outcomes, and study design } \\
\text { (PICOS). }\end{array}$ \\
\hline
\end{tabular}

\begin{tabular}{|c|c|c|c|}
\hline Protocol and registration & 5 & $\begin{array}{l}\text { Indicate if a review protocol exists, if and where it can be accessed (e.g., } \\
\text { Web address), and, if available, provide registration information including } \\
\text { registration number. }\end{array}$ & $\begin{array}{l}4 \text { and Supplement } \\
\text { data } 1\end{array}$ \\
\hline Eligibility criteria & 6 & $\begin{array}{l}\text { Specify study characteristics (e.g., PICOS, length of follow-up) and report } \\
\text { characteristics (e.g., years considered, language, publication status) used as } \\
\text { criteria for eligibility, giving rationale. }\end{array}$ & 5 \\
\hline Information sources & 7 & $\begin{array}{l}\text { Describe all information sources (e.g., databases with dates of coverage, } \\
\text { contact with study authors to identify additional studies) in the search and } \\
\text { date last searched. }\end{array}$ & 5 \\
\hline Search & 8 & $\begin{array}{l}\text { Present full electronic search strategy for at least one database, including any } \\
\text { limits used, such that it could be repeated. }\end{array}$ & $\begin{array}{l}4 \text { and Supplement } \\
\text { data } 1\end{array}$ \\
\hline Study selection & 9 & $\begin{array}{l}\text { State the process for selecting studies (i.e., screening, eligibility, included in } \\
\text { systematic review, and, if applicable, included in the meta-analysis). }\end{array}$ & 5 \\
\hline Data collection process & 10 & $\begin{array}{l}\text { Describe method of data extraction from reports (e.g., piloted forms, } \\
\text { independently, in duplicate) and any processes for obtaining and confirming } \\
\text { data from investigators. }\end{array}$ & 5 \\
\hline Data items & 11 & $\begin{array}{l}\text { List and define all variables for which data were sought (e.g., PICOS, funding } \\
\text { sources) and any assumptions and simplifications made. }\end{array}$ & 5 \\
\hline $\begin{array}{l}\text { Risk of bias in individual } \\
\text { studies }\end{array}$ & 12 & $\begin{array}{l}\text { Describe methods used for assessing risk of bias of individual studies } \\
\text { (including specification of whether this was done at the study or outcome } \\
\text { level), and how this information is to be used in any data synthesis. }\end{array}$ & N/A \\
\hline Summary measures & 13 & State the principal summary measures (e.g., risk ratio, difference in means). & 5 \\
\hline Synthesis of results & 14 & $\begin{array}{l}\text { Describe the methods of handling data and combining results of studies, if } \\
\left.\text { done, including measures of consistency (e.g., } I^{2}\right) \text { for each meta-analysis. }\end{array}$ & 6 \\
\hline Section/topic & \# & Checklist item & Reported on page \# \\
\hline Risk of bias across studies & 15 & $\begin{array}{l}\text { Specify any assessment of risk of bias that may affect the cumulative } \\
\text { evidence (e.g., publication bias, selective reporting within studies). }\end{array}$ & N/A \\
\hline Additional analyses & 16 & $\begin{array}{l}\text { Describe methods of additional analyses (e.g., sensitivity or subgroup } \\
\text { analyses, meta-regression), if done, indicating which were pre-specified. }\end{array}$ & N/A \\
\hline
\end{tabular}


RESULTS

\begin{tabular}{|c|c|c|c|}
\hline Study selection & 17 & $\begin{array}{l}\text { Give numbers of studies screened, assessed for eligibility, and included in the } \\
\text { review, with reasons for exclusions at each stage, ideally with a flow diagram. }\end{array}$ & $6-7$ \\
\hline Study characteristics & 18 & $\begin{array}{l}\text { For each study, present characteristics for which data were extracted (e.g., } \\
\text { study size, PICOS, follow-up period) and provide the citations. }\end{array}$ & Table 1 \\
\hline Risk of bias within studies & 19 & $\begin{array}{l}\text { Present data on risk of bias of each study and, if available, any outcome level } \\
\text { assessment (see item 12). }\end{array}$ & N/A \\
\hline $\begin{array}{l}\text { Results of individual } \\
\text { studies }\end{array}$ & 20 & $\begin{array}{l}\text { For all outcomes considered (benefits or harms), present, for each study: (a) } \\
\text { simple summary data for each intervention group (b) effect estimates and } \\
\text { confidence intervals, ideally with a forest plot. }\end{array}$ & Figure 2 \\
\hline Synthesis of results & 21 & $\begin{array}{l}\text { Present results of each meta-analysis done, including confidence intervals } \\
\text { and measures of consistency. }\end{array}$ & 7 \\
\hline Risk of bias across studies & 22 & Present results of any assessment of risk of bias across studies (see Item 15). & N/A \\
\hline Additional analysis & 23 & $\begin{array}{l}\text { Give results of additional analyses, if done (e.g., sensitivity or subgroup } \\
\text { analyses, meta-regression [see Item 16]). }\end{array}$ & N/A \\
\hline \multicolumn{4}{|l|}{ DISCUSSION } \\
\hline Summary of evidence & 24 & $\begin{array}{l}\text { Summarize the main findings including the strength of evidence for each } \\
\text { main outcome; consider their relevance to key groups (e.g., healthcare } \\
\text { providers, users, and policy makers). }\end{array}$ & $7-9$ \\
\hline Limitations & 25 & $\begin{array}{l}\text { Discuss limitations at study and outcome level (e.g., risk of bias), and at } \\
\text { review-level (e.g., incomplete retrieval of identified research, reporting bias). }\end{array}$ & 9 \\
\hline Conclusions & 26 & $\begin{array}{l}\text { Provide a general interpretation of the results in the context of other } \\
\text { evidence, and implications for future research. }\end{array}$ & 10 \\
\hline \multicolumn{4}{|l|}{ FUNDING } \\
\hline Funding & 27 & $\begin{array}{l}\text { Describe sources of funding for the systematic review and other support } \\
\text { (e.g., supply of data); role of funders for the systematic review. }\end{array}$ & 10 \\
\hline
\end{tabular}

From: Moher D, Liberati A, Tetzlaff J, Altman DG, The PRISMA Group. Preferred Reporting Items for Systematic Reviews and Meta-Analyses: The PRISMA Statement. PLoS Med 2009;6:e1000097. 